\title{
Fixed Point Approximation of Nonexpansive Mappings on a Nonlinear Domain
}

\author{
Safeer Hussain Khan \\ Department of Mathematics, Statistics and Physics, Qatar University, Doha 2713, Qatar \\ Correspondence should be addressed to Safeer Hussain Khan; safeer@qu.edu.qa
}

Received 5 February 2014; Accepted 8 March 2014; Published 31 March 2014

Academic Editor: Abdul Latif

Copyright (C) 2014 Safeer Hussain Khan. This is an open access article distributed under the Creative Commons Attribution License, which permits unrestricted use, distribution, and reproduction in any medium, provided the original work is properly cited.

\begin{abstract}
We use a three-step iterative process to prove some strong and $\Delta$-convergence results for nonexpansive mappings in a uniformly convex hyperbolic space, a nonlinear domain. Three-step iterative processes have numerous applications and hyperbolic spaces contain Banach spaces (linear domains) as well as CAT(0) spaces. Thus our results can be viewed as extension and generalization of several known results in uniformly convex Banach spaces as well as CAT(0) spaces.
\end{abstract}

\section{Introduction and Preliminaries}

Approximating fixed points of nonlinear mappings using different iterative processes on different domains has remained at the heart of fixed point theory. Nonexpansive mappings constitute one of the most important classes of nonlinear mappings which have remained a crucial part of such studies. Another important role is that of ambient spaces in this regard. Banach spaces (linear domains) with some geometric structure have been studied extensively: one of such structures is convexity. Since every Banach space is a vector space, it is easier to assign a convex structure to it. However, metric spaces do not enjoy this structure. Takahashi [1] introduced the notion of convex metric spaces and studied the fixed point theory for nonexpansive mappings in this setting. Later on, several attempts were made to introduce different convex structures on a metric space. One such convex structure is available in a hyperbolic space introduced by Kohlenbach [2] . Kohlenbach hyperbolic space [2] is more restrictive than the hyperbolic space introduced in [3] and more general than the concept of hyperbolic space in [4]. Spaces like CAT(0) and Banach are special cases of a hyperbolic space. The class of hyperbolic spaces also contains Hadamard manifolds, Hilbert ball equipped with the hyperbolic metric [5], $\mathbb{R}$ trees, and Cartesian products of Hilbert balls as special cases. Many authors have worked on hyperbolic spaces; see for example, $[6,7]$ and the references cited therein. Finally, an iterative process to be used for approximation of fixed point is very important. Several iterative processes having various numbers of steps have been employed for the purpose. Very famous Mann iteration process is a one-step process, while Ishikawa process is a two-step process among others. Glowinski and Le Tallec [8] used a three-step iterative process to obtain approximate solutions of the elastoviscoplasticity problem, liquid crystal theory, and eigenvalue computation. They observed that a three-step iterative process is better than a two- and a one-step iterative process in giving numerical results. This was again testified in the study of Abbas and Nazir [9]. Haubruge et al. [10] analyzed convergence of a three-step iterative process of Glowinski and Le Tallec [8] and applied it to obtain new splitting type iterations for solving variational inequalities, separable convex programming, and minimization of a sum of convex functions. They also proved that a three-step iterative process lead to highly paralleled iterations under certain conditions. Thus we conclude that studying three-step iterative processes is very important in solving various numerical problems arising in pure and applied sciences.

The purpose of this paper is to investigate $\Delta$-convergence as well as strong convergence of a three-step iterative process (to be given later) for nonexpansive maps on a nonlinear domain of hyperbolic spaces. As mentioned above, the class of uniformly convex hyperbolic spaces includes several types of spaces including those of uniformly convex Banach spaces 
as well as CAT(0) spaces. This shows that our results extend and improve the corresponding results for uniformly convex Banach spaces as well as CAT(0) spaces at the same time and using one of the well-applied three-step iterative processes.

Throughout this paper, $\mathbb{N}$ stands for the set of natural numbers. Let $(X, d)$ be a metric space and $K$ a nonempty subset of $X$. A mapping $T: K \rightarrow K$ is said to be nonexpansive if $d(T x, T y) \leq d(x, y)$ for all $x, y \in K$. The notation $F(T)$ has been reserved for the set of fixed points of $T$.

A hyperbolic space [2] is a triple $(X, d, W)$ where $(X, d)$ is a metric space and $W: X^{2} \times[0,1] \rightarrow X$ is such that

$$
\begin{aligned}
& \text { (W1) } d(u, W(x, y, \alpha)) \leq(1-\alpha) d(u, x)+\alpha d(u, y), \\
& \text { (W2) } d(W(x, y, \alpha), W(x, y, \beta))=|\alpha-\beta| d(x, y), \\
& \text { (W3) } W(x, y, \alpha)=W(y, x,(1-\alpha)), \\
& \text { (W4) } d(W(x, z, \alpha), W(y, u, \alpha)) \leq(1-\alpha) d(x, y)+\alpha d(z, u),
\end{aligned}
$$

for all $x, y, z, u \in X$ and $\alpha, \beta \in[0,1]$.

If $(X, d, W)$ satisfies only (W1), then it coincides with the convex metric space introduced by Takahashi [1]. A subset $K$ of a hyperbolic space $X$ is called convex if $W(x, y, \alpha) \in K$ for all $x, y \in K$ and $\alpha \in[0,1]$.

A hyperbolic space $(X, d, W)$ is said to be

(i) strictly convex [1] if, for any $x, y \in X$ and $\lambda \in[0,1]$, there exists a unique element $z \in X$ such that

$d(z, x)=\lambda d(x, y), \quad d(z, y)=(1-\lambda) d(x, y) ;$

(ii) uniformly convex [11] if, for all $u, x, y \in X, r>0$ and $\varepsilon \in(0,2]$, there exists a $\delta \in(0,1]$ such that

$$
\left.\begin{array}{l}
d(x, u) \leq r \\
d(y, u) \leq r \\
d(x, y) \geq \varepsilon r
\end{array}\right\} \Longrightarrow d\left(W\left(x, y, \frac{1}{2}\right), u\right) \leq(1-\delta) r
$$

A map $\eta:(0, \infty) \times(0,2] \rightarrow(0,1]$ which provides such a $\delta=\eta(r, \varepsilon)$ for given $r>0$ and $\varepsilon \in(0,2]$ is called modulus of uniform convexity. We call $\eta$ monotone if it decreases with $r$ (for a fixed $\varepsilon$ ). A uniformly convex hyperbolic space is strictly convex (see [12]).

In all the iterative processes to follow, we fix a given $x_{1}$ in $K$ (a subset of the ambient space) as a starting point of the process and $T: K \rightarrow K$ a nonexpansive mapping unless stated otherwise. We know that Picard and Mann iterative processes are defined, respectively, as

$$
\begin{gathered}
x_{n+1}=T x_{n}, \quad n \in \mathbb{N}, \\
x_{n+1}=\left(1-\alpha_{n}\right) x_{n}+\alpha_{n} T x_{n}, \quad n \in \mathbb{N},
\end{gathered}
$$

where $\left\{\alpha_{n}\right\}$ is in $(0,1)$.

In an attempt to develop an iterative process whose rate of convergence is faster than the Picard iterative, Agarwal et al. [13] introduced the following two-step iterative process:

$$
\begin{aligned}
& x_{n+1}=\left(1-\alpha_{n}\right) T x_{n}+\alpha_{n} T y_{n}, \\
& y_{n}=\left(1-\beta_{n}\right) x_{n}+\beta_{n} T x_{n}, \quad n \in \mathbb{N},
\end{aligned}
$$

where $\left\{\alpha_{n}\right\}$ and $\left\{\beta_{n}\right\}$ are in $(0,1)$. They showed that this process converges at a rate the same as that of Picard process and faster than Mann process for contractions. Continuing with the same question, Sahu [14] proved that this process converges at a rate faster than both Picard and Mann for contractions. He also gave a numerical example in support of his analytic proof.

Recently, Abbas and Nazir [9] considered the following three-step iterative process in Banach spaces:

$$
\begin{aligned}
& x_{n+1}=\left(1-\alpha_{n}\right) T y_{n}+\alpha_{n} T z_{n}, \\
& y_{n}=\left(1-\beta_{n}\right) T x_{n}+\beta_{n} T z_{n}, \\
& z_{n}=\left(1-\gamma_{n}\right) x_{n}+\gamma_{n} T x_{n}, \quad n \in \mathbb{N},
\end{aligned}
$$

where $\left\{\alpha_{n}\right\},\left\{\beta_{n}\right\}$ and $\left\{\gamma_{n}\right\}$ are in $(0,1)$.

They proved that it is faster than all of Picard, Mann, and Agarwal et al.s while supporting their analytic proof by a numerical example. They claimed that their process was independent of all the processes just mentioned in the sense that neither can be deduced from this process and vice versa. They proved some weak and strong convergence results using this iterative process for nonexpansive mappings in Banach spaces (a linear domain).

Keeping in mind the above discussion (about mappings, ambient spaces, and iterative processes), we first write the iterative process (5) in the language of hyperbolic spaces as

$$
\begin{aligned}
& x_{n+1}=W\left(T y_{n}, T z_{n}, \alpha_{n}\right), \\
& y_{n}=W\left(T x_{n}, T z_{n}, \beta_{n}\right), \\
& z_{n}=W\left(x_{n}, T x_{n}, \gamma_{n}\right), \quad n \in \mathbb{N},
\end{aligned}
$$

where $\left\{\alpha_{n}\right\},\left\{\beta_{n}\right\}$ and $\left\{\gamma_{n}\right\}$ are in $(0,1)$.

Note that (6) is a three-step iterative process. To explain and simplify the already mentioned purpose of our paper, we say that we apply iterative process (6) to approximate fixed points of nonexpansive mappings in a hyperbolic space.

Let us now turn to some prerequisites as follows.

The concept of $\Delta$-convergence in a metric space was introduced by Lim [15]. $\Delta$-convergence in CAT(0) spaces has been investigated initially by Dhompongsa and Panyanak [16]. See also Khan et al. [6], Abbas and Khan [17], and Khan and Abbas [18].

Let $\left\{x_{n}\right\}$ be a bounded sequence in a hyperbolic space $X$. For $x \in X$, we define a continuous functional $r\left(\cdot,\left\{x_{n}\right\}\right): X \rightarrow$ $[0, \infty)$ by

$$
r\left(x,\left\{x_{n}\right\}\right)=\limsup _{n \rightarrow \infty} d\left(x, x_{n}\right) .
$$

The asymptotic radius $\rho=r\left(\left\{x_{n}\right\}\right)$ of $\left\{x_{n}\right\}$ is defined as

$$
\rho=\inf \left\{r\left(x,\left\{x_{n}\right\}\right): x \in X\right\} .
$$

The asymptotic center of a bounded sequence $\left\{x_{n}\right\}$ with respect to a subset $K$ of $X$ is defined as

$$
\begin{aligned}
& A_{K}\left(\left\{x_{n}\right\}\right) \\
& \quad=\left\{x \in X: r\left(x,\left\{x_{n}\right\}\right) \leq r\left(y,\left\{x_{n}\right\}\right) \text { for any } y \in K\right\} .
\end{aligned}
$$


If the asymptotic center is taken with respect to $X$, then it is simply denoted by $A\left(\left\{x_{n}\right\}\right)$. It is known that uniformly convex Banach spaces and CAT(0) spaces enjoy the property that bounded sequences have unique asymptotic centers with respect to closed convex subsets. In case of hyperbolic spaces, we have the following result.

Lemma 1 (see [19]). Let $(X, d, W)$ be a complete uniformly convex hyperbolic space with monotone modulus of uniform convexity. Then every bounded sequence $\left\{x_{n}\right\}$ in $X$ has a unique asymptotic center with respect to any nonempty closed convex subset $K$ of $X$.

A sequence $\left\{x_{n}\right\}$ in $X$ is said to $\Delta$-converge to $x \in X$ if $x$ is the unique asymptotic center of $\left\{u_{n}\right\}$ for every subsequence $\left\{u_{n}\right\}$ of $\left\{x_{n}\right\}$. In this case, $x$ is called $\Delta$-limit of $\left\{x_{n}\right\}$ and is written as $\Delta-\lim _{n} x_{n}=x$.

The following useful lemma has been taken from Khan et al. [6].

Lemma 2 (see [6]). Let $(X, d, W)$ be a uniformly convex hyperbolic space with monotone modulus of uniform convexity $\eta$. Let $x \in X,\left\{\alpha_{n}\right\}$ be a sequence in $[b, c]$ for some $b, c \in(0,1)$ and $\left\{x_{n}\right\},\left\{y_{n}\right\}$ sequences in $X$. If $\limsup _{n \rightarrow \infty} d\left(x_{n}, x\right) \leq r, \limsup _{n \rightarrow \infty} d\left(y_{n}, x\right) \leq$ $r$, and $\lim _{n \rightarrow \infty} d\left(W\left(x_{n}, y_{n}, \alpha_{n}\right), x\right)=r$ for some $r \geq 0$, then $\lim _{n \rightarrow \infty} d\left(x_{n}, y_{n}\right)=0$.

A sequence $\left\{x_{n}\right\}$ in a metric space $X$ is said to be Fejér monotone with respect to $K$ (a subset of $X$ ) if $d\left(x_{n+1}, p\right) \leq$ $d\left(x_{n}, p\right)$ for all $p \in K$ and for all $n \in \mathbb{N}$.

Lemma 3 (see [20]). Let $K$ be a nonempty closed subset of a complete metric space $(X, d)$ and let $\left\{x_{n}\right\}$ be Fejér monotone with respect to $K$. Then $\left\{x_{n}\right\}$ converges to some $p \in K$ if and only if $\lim _{n \rightarrow \infty} d\left(x_{n}, K\right)=0$.

A map $T: K \rightarrow K$ is semicompact if any bounded sequence $\left\{x_{n}\right\}$ satisfying $d\left(x_{n}, T x_{n}\right) \rightarrow 0$ as $n \rightarrow \infty$, has a convergent subsequence. A map $T: K \rightarrow K$ is said to satisfy condition (I) in [21] if there is a nondecreasing function $f$ : $[0, \infty) \rightarrow[0, \infty)$ with $f(0)=0, f(t)>0$ for all $t \in(0, \infty)$ such that

$$
d(x, T x) \geq f(d(x, F(T))),
$$

for all $x \in K$, where $d(x, F(T))=\inf \{d(x, p): p \in F(T)\}$.

\section{Fixed Point Approximation}

We start our main section with the following.

Lemma 4. Let $K$ be a nonempty closed convex subset of a hyperbolic space $X$ and let $T$ be a nonexpansive self-map on $K$ such that $F(T) \neq \emptyset$. Then $\left\{x_{n}\right\}$ as defined in (6) is Fejér monotone with respect to $F(T)$.
Proof. Let $p \in F(T)$. Using (6), we have

$$
\begin{aligned}
d\left(z_{n}, p\right) & =d\left(W\left(x_{n}, T x_{n}, \gamma_{n}\right), p\right) \\
& \leq\left(1-\gamma_{n}\right) d\left(x_{n}, p\right)+\gamma_{n} d\left(T x_{n}, p\right) \\
& \leq\left(1-\gamma_{n}\right) d\left(x_{n}, p\right)+\gamma_{n} d\left(x_{n}, p\right) \\
& =d\left(x_{n}, p\right) .
\end{aligned}
$$

Next,

$$
\begin{aligned}
d\left(y_{n}, p\right) & =d\left(W\left(T x_{n}, T z_{n}, \beta_{n}\right), p\right) \\
& \leq\left(1-\beta_{n}\right) d\left(T x_{n}, p\right)+\beta_{n} d\left(T z_{n}, p\right) \\
& \leq\left(1-\beta_{n}\right) d\left(x_{n}, p\right)+\beta_{n} d\left(z_{n}, p\right) \\
& \leq\left(1-\beta_{n}\right) d\left(x_{n}, p\right)+\beta_{n} d\left(x_{n}, p\right) \text { by (11) } \\
& =d\left(x_{n}, p\right) .
\end{aligned}
$$

Thus

$$
\begin{aligned}
d\left(x_{n+1}, p\right)= & d\left(W\left(T y_{n}, T z_{n}, \alpha_{n}\right), p\right) \\
\leq & \left(1-\alpha_{n}\right) d\left(T y_{n}, p\right)+\alpha_{n} d\left(T z_{n}, p\right) \\
\leq & \left(1-\alpha_{n}\right) d\left(y_{n}, p\right)+\alpha_{n} d\left(z_{n}, p\right) \\
\leq & \left(1-\alpha_{n}\right) d\left(x_{n}, p\right) \\
& +\alpha_{n} d\left(x_{n}, p\right) \text { by (11) and (12) } \\
= & d\left(x_{n}, p\right) .
\end{aligned}
$$

That is, $d\left(x_{n+1}, p\right) \leq d\left(x_{n}, p\right)$ for all $p \in F(T)$. Thus $\left\{x_{n}\right\}$ is Fejér monotone with respect to $F(T)$.

Remarks 1. The following are immediate consequences of the above lemma:

(1) $\lim _{n \rightarrow \infty} d\left(x_{n}, p\right)$ exists for all $p \in F(T)$;

(2) $\lim _{n \rightarrow \infty} d\left(x_{n}, F(T)\right)$ exists;

(3) $\left\{x_{n}\right\}$ is bounded.

Lemma 5. Let $K$ be a nonempty closed convex subset of a uniformly convex hyperbolic space $X$ with monotone modulus of uniform convexity $\eta$. Let $T$ be a nonexpansive self-map on $K$ such that $F(T) \neq \emptyset$. Let $\left\{x_{n}\right\}$ be as defined in (6). Then

$$
\lim _{n \rightarrow \infty} d\left(x_{n}, T x_{n}\right)=0 .
$$

Proof. Let $p \in F(T)$. By Lemma 4, it follows that $\lim _{n \rightarrow \infty} d\left(x_{n}, p\right)$ exists. Assume that $\lim _{n \rightarrow \infty} d\left(x_{n}, p\right)=c$ where $c \geq 0$. Note that

$$
\begin{aligned}
\limsup _{n \rightarrow \infty} d\left(T z_{n}, p\right) & \leq \limsup _{n \rightarrow \infty} d\left(z_{n}, p\right) \\
& \leq \lim _{n \rightarrow \infty} d\left(x_{n}, p\right) \\
& =c .
\end{aligned}
$$


Similarly,

$$
\limsup _{n \rightarrow \infty} d\left(T y_{n}, p\right) \leq c
$$

Since $\lim _{n \rightarrow \infty} d\left(x_{n+1}, p\right)=\lim _{n \rightarrow \infty} d\left(W\left(T y_{n}, T z_{n}, \alpha_{n}\right), p\right)=$ $c$, Lemma 2 gives

$$
\lim _{n \rightarrow \infty} d\left(T y_{n}, T z_{n}\right)=0
$$

Next,

$$
\begin{aligned}
d\left(x_{n+1}, p\right)= & d\left(W\left(T y_{n}, T z_{n}, \alpha_{n}\right), p\right) \\
\leq & \left(1-\alpha_{n}\right) d\left(T y_{n}, p\right)+\alpha_{n} d\left(T z_{n}, p\right) \\
\leq & \left(1-\alpha_{n}\right) d\left(T y_{n}, p\right)+\alpha_{n} d\left(T z_{n}, T y_{n}\right) \\
& +\alpha_{n} d\left(T y_{n}, p\right) \\
\leq & d\left(T y_{n}, p\right)+\alpha_{n} d\left(T z_{n}, T y_{n}\right) \\
\leq & d\left(y_{n}, p\right)+\alpha_{n} d\left(T z_{n}, T y_{n}\right)
\end{aligned}
$$

implies by virtue of (17) that

$$
\liminf _{n \rightarrow \infty} d\left(y_{n}, p\right) \geq c .
$$

But by (12), lim $\sup _{n \rightarrow \infty} d\left(y_{n}, p\right) \leq c$; hence

$$
\lim _{n \rightarrow \infty} d\left(y_{n}, p\right)=\lim _{n \rightarrow \infty} d\left(W\left(T x_{n}, T z_{n}, \beta_{n}\right), p\right)=c .
$$

Since $\quad \lim \sup _{n \rightarrow \infty} d\left(T x_{n}, p\right) \leq \quad c \quad$ and $\lim \sup _{n \rightarrow \infty} d\left(T z_{n}, p\right) \leq c$, Lemma 2 guarantees

$$
\lim _{n \rightarrow \infty} d\left(T x_{n}, T z_{n}\right)=0
$$

because of (20).

Moreover,

$$
\begin{aligned}
d\left(y_{n}, p\right)= & d\left(W\left(T x_{n}, T z_{n}, \beta_{n}\right), p\right) \\
\leq & \left(1-\beta_{n}\right) d\left(T x_{n}, p\right)+\beta_{n} d\left(T z_{n}, p\right) \\
\leq & \left(1-\beta_{n}\right) d\left(T x_{n}, T z_{n}\right)+\left(1-\beta_{n}\right) d\left(T z_{n}, p\right) \\
& +\beta_{n} d\left(T z_{n}, p\right) \\
= & \left(1-\beta_{n}\right) d\left(T x_{n}, T z_{n}\right)+d\left(T z_{n}, p\right) \\
\leq & \left(1-\beta_{n}\right) d\left(T x_{n}, T z_{n}\right)+d\left(z_{n}, p\right)
\end{aligned}
$$

yields by virtue of (21) that

$$
\liminf _{n \rightarrow \infty} d\left(z_{n}, p\right) \geq c
$$

But by (11), $\lim \sup _{n \rightarrow \infty} d\left(z_{n}, p\right) \leq c$; hence

$$
\lim _{n \rightarrow \infty} d\left(z_{n}, p\right)=\lim _{n \rightarrow \infty} d\left(W\left(x_{n}, T x_{n}, \gamma_{n}\right), p\right)=c .
$$

Thus from Lemma 2, we obtain

$$
\lim _{n \rightarrow \infty} d\left(x_{n}, T x_{n}\right)=0 .
$$

The following are our strong convergence results.
Theorem 6. Let $K$ be a nonempty closed convex subset of a complete uniformly convex hyperbolic space $X$ with monotone modulus of uniform convexity $\eta$ and let $T$ be a nonexpansive self-map on $K$ such that $F(T) \neq \emptyset$. Suppose that $T$ satisfies condition (I) in [21]. Then the sequence $\left\{x_{n}\right\}$ defined in (6) converges strongly to $p \in F(T)$.

Proof. By Lemma 4, it follows that $\lim _{n \rightarrow \infty} d\left(x_{n}, p\right)$ exists for all $p \in F(T)$ and hence $\lim _{n \rightarrow \infty} d\left(x_{n}, F(T)\right)$ exists. Also, by Lemma $5, \lim _{n \rightarrow \infty} d\left(x_{n}, T x_{n}\right)=0$. By using condition (I) in [21] we get $\lim _{n \rightarrow \infty} f\left(d\left(x_{n}, F(T)\right)\right)=0$. Since $f$ is nondecreasing with $f(0)=0$, it follows that $\lim _{n \rightarrow \infty} d\left(x_{n}, F(T)\right)=0$. Again by Lemma $4,\left\{x_{n}\right\}$ is Fejér monotone with respect to $F(T)$. Thus Lemma 3 implies that $\left\{x_{n}\right\}$ converges strongly to a point $p$ in $F(T)$.

Theorem 7. Let $K$ be a nonempty closed convex subset of a complete uniformly convex hyperbolic space $X$ with monotone modulus of uniform convexity $\eta$ and let $T$ be a nonexpansive self-map on $K$ such that $F(T) \neq \emptyset$. Suppose that either $K$ is compact or $T$ is semicompact. Then the sequence $\left\{x_{n}\right\}$ defined in (6) converges strongly to $p \in F(T)$.

Proof. Note that the condition (I) in [21] is weaker than both the compactness of $K$ and the semicompactness of the nonexpansive mappings $T$; therefore we have the result by above theorem.

Finally, we give our $\Delta$-convergence theorem.

Theorem 8. Let $K$ be a nonempty closed convex subset of a complete uniformly convex hyperbolic space $X$ with monotone modulus of uniform convexity $\eta$ and let $T$ be a nonexpansive self-map on $K$ such that $F(T) \neq \emptyset$. Then the sequence $\left\{x_{n}\right\}$ defined by (6) $\Delta$-converges to a fixed point of $T$.

Proof. It follows from Lemma 4 that $\left\{x_{n}\right\}$ is bounded. Therefore $\left\{x_{n}\right\}$ has a $\Delta$-convergent subsequence. We now prove that every $\Delta$-convergent subsequence of $\left\{x_{n}\right\}$ has a unique $\Delta$-limit in $F(T)$. For this, let $u$ and $v$ be the $\Delta$-limits of the subsequences $\left\{u_{n}\right\}$ and $\left\{v_{n}\right\}$ of $\left\{x_{n}\right\}$, respectively. By definition $A\left(\left\{u_{n}\right\}\right)=\{u\}$ and $A\left(\left\{v_{n}\right\}\right)=\{v\}$. By Lemma 5, we have $\lim _{n \rightarrow \infty} d\left(u_{n}, T u_{n}\right)=0$. We claim that $u$ is a fixed point of T. Now

$$
\begin{aligned}
d\left(T u, u_{n}\right) & \leq d\left(T u, T u_{n}\right)+d\left(T u_{n}, u_{n}\right) \\
& \leq d\left(u, u_{n}\right)+d\left(T u_{n}, u_{n}\right)
\end{aligned}
$$

implies that

$$
\begin{aligned}
r\left(T u,\left\{u_{n}\right\}\right) & =\limsup _{n \rightarrow \infty} d\left(T u, u_{n}\right) \\
& \leq \limsup _{n \rightarrow \infty}\left[d\left(T u, T u_{n}\right)+d\left(T u_{n}, u_{n}\right)\right]
\end{aligned}
$$




$$
\begin{aligned}
& \leq \limsup _{n \rightarrow \infty}\left[d\left(u, u_{n}\right)+d\left(T u_{n}, u_{n}\right)\right] \\
& =\limsup _{n \rightarrow \infty} d\left(u, u_{n}\right) \\
& =r\left(u,\left\{u_{n}\right\}\right) .
\end{aligned}
$$

By the uniqueness of asymptotic centers, $T u=u$. Similarly, we can prove that $T v=v$. This means that both $u$ and $v$ are fixed points of $T$. What is left to prove now is that $u=v$. To this end, if $u$ and $v$ are distinct then by uniqueness of asymptotic centers,

$$
\begin{aligned}
\lim _{n \rightarrow \infty} d\left(x_{n}, u\right) & =\limsup _{n \rightarrow \infty} d\left(u_{n}, u\right) \\
& <\limsup _{n \rightarrow \infty} d\left(u_{n}, v\right) \\
& =\limsup _{n \rightarrow \infty} d\left(x_{n}, v\right) \\
& =\limsup _{n \rightarrow \infty} d\left(v_{n}, v\right) \\
& <\limsup _{n \rightarrow \infty} d\left(v_{n}, u\right) \\
& =\limsup _{n \rightarrow \infty} d\left(x_{n}, u\right) .
\end{aligned}
$$

This is a contradiction and hence the proof.

\section{Conflict of Interests}

The authors declare that they have no conflict of interests regarding the publication of this paper.

\section{References}

[1] W. Takahashi, "A convexity in metric spaces and nonexpansive mappings," Kodai Mathematical Seminar Reports, vol. 22, no. 2, pp. 142-149, 1970.

[2] U. Kohlenbach, "Some logical metatheorems with applications in functional analysis," Transactions of the American Mathematical Society, vol. 357, no. 1, pp. 89-128, 2005.

[3] K. Goebel and W. A. Kirk, "Iteration processes for nonexpansive mappings," in Topological Methods in Nonlinear Functional Analysis, S. P. Singh, S. Thomeier, and B. Watson, Eds., vol. 21 of Contemporary Mathematics, pp. 115-1123, American Mathematical Society, Providence, RI, USA, 1983.

[4] S. Reich and I. Shafrir, "Nonexpansive iterations in hyperbolic spaces," Nonlinear Analysis, vol. 15, no. 6, pp. 537-558, 1990.

[5] K. Goebel and S. Reich, Uniform Convexity, Hyperbolic Geometry, and Nonexpansive Mappings, Marcel Dekker, New York, NY, USA, 1984.

[6] A. R. Khan, H. Fukhar-ud-din, and M. A. A. Khan, "An implicit algorithm for two finite families of nonexpansive maps in hyperbolic spaces," Fixed Point Theory and Applications, vol. 2012, article 54, 2012.

[7] H. Fukhar-ud-din and M. Khan, "Convergence analysis of a general iteration schema of non-linear mappings in hyperbolic spaces," Fixed Point Theory and Applications, vol. 2013, article $238,2013$.
[8] R. Glowinski and P. Le Tallec, Augmented Lagrangian and Operator-Splitting Methods in Nonlinear Mechanics, Society for Industrial and Applied Mathematics, Philadelphia, Pa, USA, 1989.

[9] M. Abbas and T. Nazir, "A new faster iteration process applied to constrained minimization and feasibility problems," Mathematicki Vesnik, vol. 106, pp. 1-12, 2013.

[10] S. Haubruge, V. H. Nguyen, and J. J. Strodiot, "Convergence analysis and applications of the Glowinski-Le Tallec splitting method for finding a zero of the sum of two maximal monotone operators," Journal of Optimization Theory and Applications, vol. 97, no. 3, pp. 645-673, 1998.

[11] T. Shimizu and W. Takahashi, "Fixed points of multivalued mappings in certain convex metric spaces," Topological Methods in Nonlinear Analysis, vol. 8, no. 1, pp. 197-203, 1996.

[12] L. Leustean, "A quadratic rate of asymptotic regularity for CAT(0) spaces," Journal of Mathematical Analysis and Applications, vol. 325, no. 1, pp. 386-399, 2007.

[13] R. P. Agarwal, D. O'Regan, and D. R. Sahu, "Iterative construction of fixed points of nearly asymptotically nonexpansive mappings," Journal of Nonlinear and Convex Analysis, vol. 8, no. 1, pp. 61-79, 2007.

[14] D. R. Sahu, "Applications of the S-iteration process to constrained minimization problems and split feasibility problems," Fixed Point Theory, vol. 12, no. 1, pp. 187-204, 2011.

[15] T. C. Lim, "Remarks on some fixed point theorems," Proceedings of the American Mathematical Society, vol. 60, pp. 179-182, 1976.

[16] S. Dhompongsa and B. Panyanak, "On $\Delta$-convergence theorems in CAT(0) spaces," Computers and Mathematics with Applications, vol. 56, no. 10, pp. 2572-2579, 2008.

[17] M. Abbas and S. H. Khan, "Some $\Delta$-convergence theorems in CAT(0) spaces," Hacettepe Journal of Mathematics and Statistics, vol. 40, no. 4, pp. 563-569, 2011.

[18] S. H. Khan and M. Abbas, "Strong and $\Delta$-convergence of some iterative schemes in CAT(0) spaces," Computers and Mathematics with Applications, vol. 61, no. 1, pp. 109-116, 2011.

[19] L. Leustean, "Nonexpansive iterations in uniformly convex $W$ hyperbolic spaces," in Nonlinear Analysis and Optimization I: Nonlinear Analysis, A. Leizarowitz, B. S. Mordukhovich, I. Shafrir, and A. Zaslavski, Eds., vol. 513 of Contemporary Mathematics, pp. 193-209, American Mathematical Society, 2010.

[20] H. H. Bauschke and P. L. Combettes, Convex Analysis and Monotone Operator Theory in Hilbert Spaces, Springer, New York, NY, USA, 2011.

[21] H. F. Senter and W. G. Dotson,, "Approximating fixed points of nonexpansive mappings," Proceedings of the American Mathematical Society, vol. 44, no. 2, pp. 375-380, 1974. 


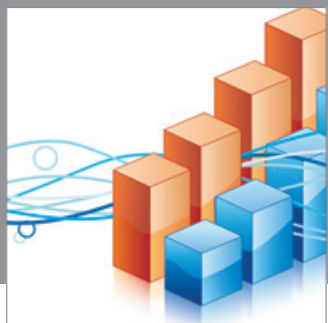

Advances in

Operations Research

mansans

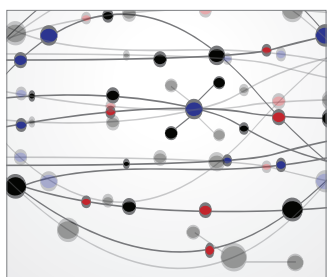

The Scientific World Journal
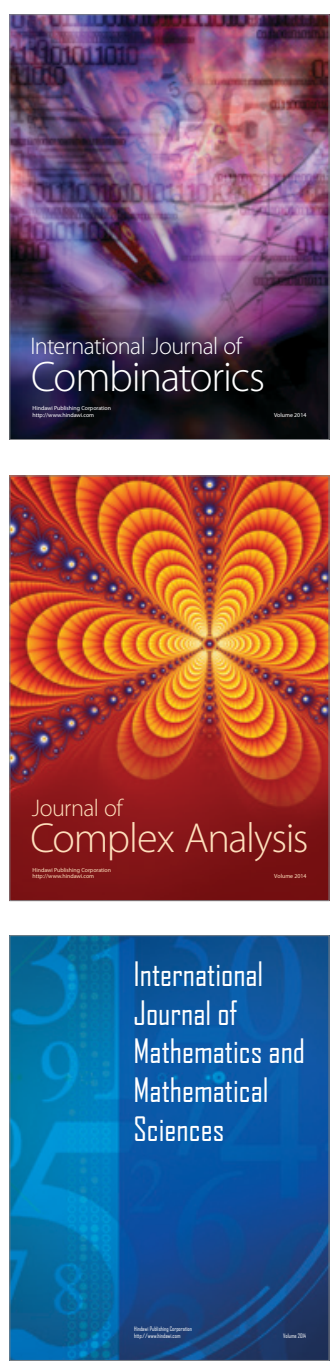
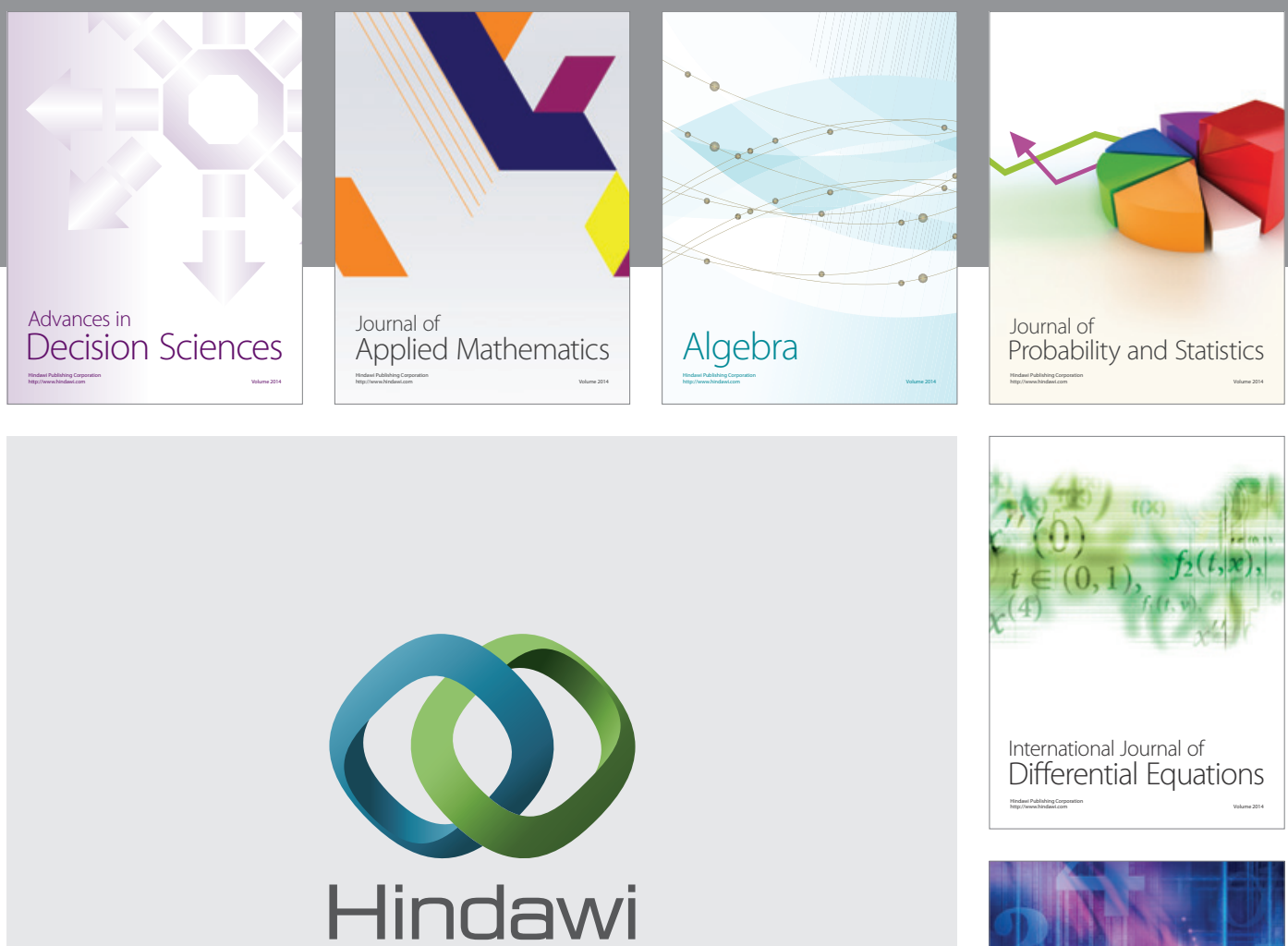

Submit your manuscripts at http://www.hindawi.com
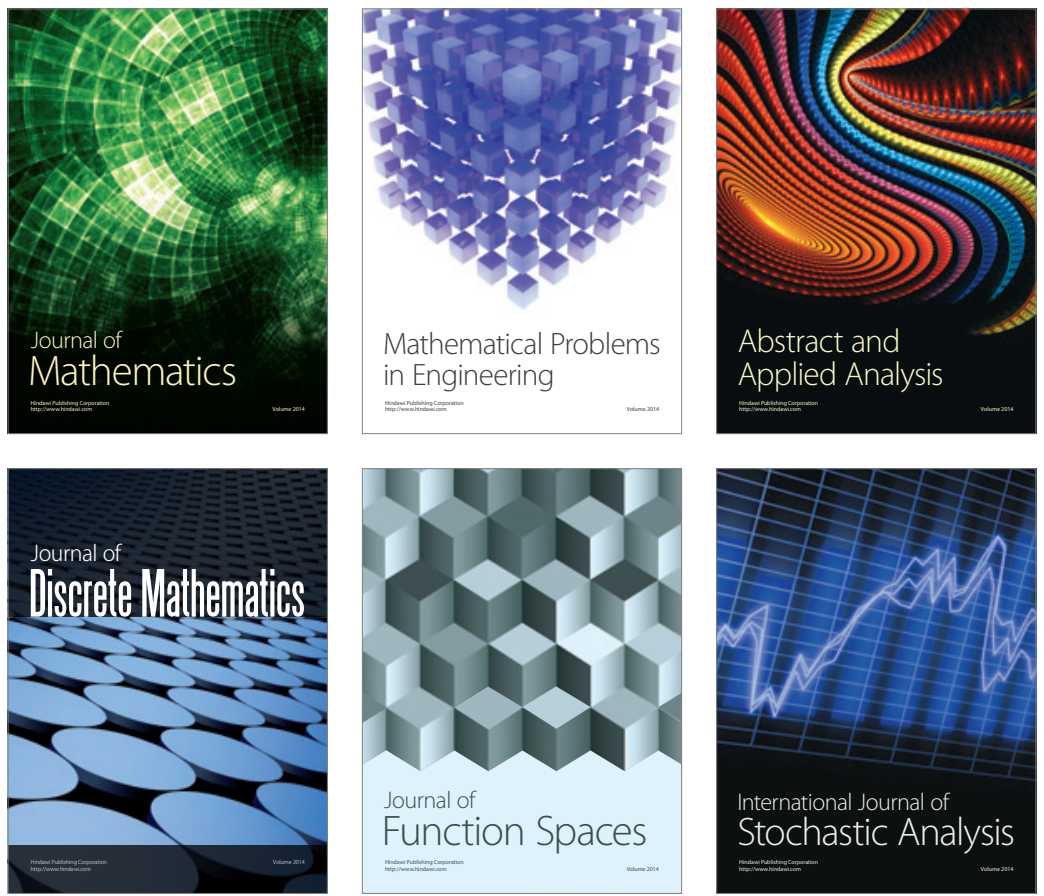

Journal of

Function Spaces

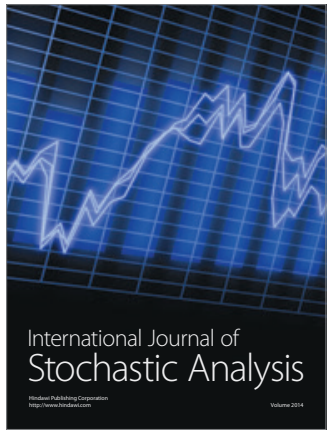

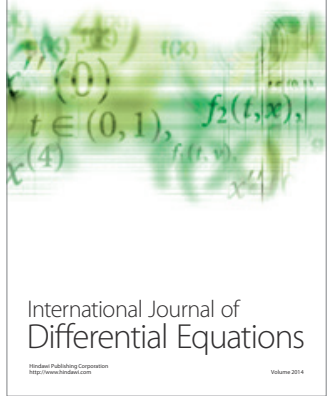
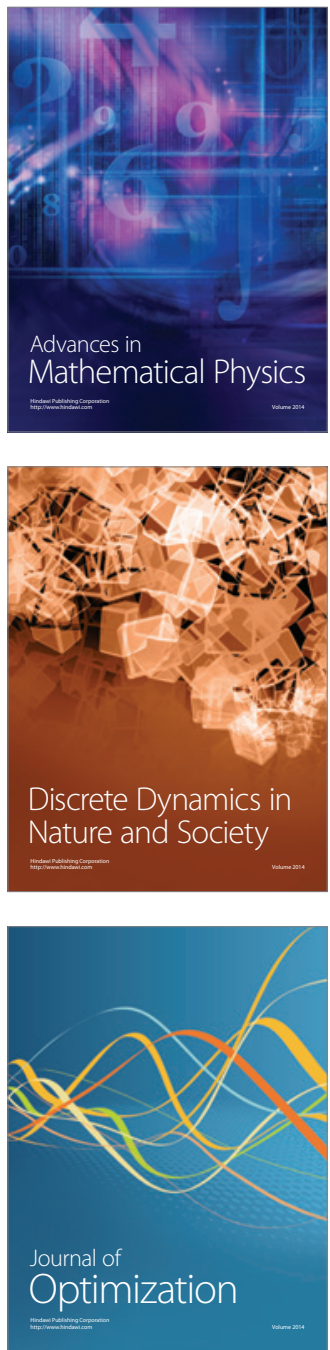